\title{
ESCOVANDO A HISTÓRIA COLONIAL A CONTRAPELO: Teoria da Memória como Base Epistemológica para uma Teoria Crítica dos Direitos Humanos
}

\author{
Nelson Camatta Moreira \\ Autor correspondente. Faculdade de Direito de Vitória - FDV - Núcleo Docente Estruturante. Rua Juiz Alexandre Martins de Castro \\ Filho, 215 - Santa Lucia. Vitória/ES, Brasil. CEP 29056-295. http://lattes.cnpq.br/2535094687665916. \\ https://orcid.org/0000-0002-8295-4275.nelsoncmoreira@hotmail.com \\ Antonio Leal de Oliveira \\ Faculdade de Direito de Vitória - FDV. Vitória/ES, Brasil. \\ Silvana Pereira Carneiro \\ Faculdade de Direito de Vitória - FDV. Vitória/ES, Brasil.
}

RESUMO

Este artigo tem como objetivo apresentar a interseção entre a teoria da memória de Walter Benjamin e o pensamento decolonial de Enrique Dussel como fundamentos epistemológicos para uma Teoria Crítica dos Direitos Humanos. Nesse sentido, a crítica ao progresso, defendida por Benjamin, e a crítica ao discurso colonizador eurocêntrico, empreendida por Dussel, permitirão a narrativa de uma nova história, de uma história "escovada a contrapelo" (BENJAMIN, 1994). A preocupação de ambas as teorias com as vítimas silenciadas pela história oficial, nos leva a propor uma teoria crítica dos direitos humanos que tenha em conta uma exigência de memória e de justiça para essas vítimas.

Palavras-chave: progresso; decolonialidade; teoria crítica dos direitos humanos.

\section{BRUSHING COLONIAL HISTORY AGAINST THE GRAIN: SOME BASES FOR A CRITICAL THEORY OF HUMAN RIGHTS}

ABSTRACT

This article aims to discuss the approach of two significant passages from the works by Walter Benjamin and Enrique Dussel, namely, the vehement criticism about the ideal of progress and decoloniality, respectively. Thus, at the moment in which Walter Benjamin, when brushing story against the grain, describes that history needs to be told differently as away of redemption of humanity itself, he connects with Enrique Dussel, who, in turn, tries to think from starting points that are inherent to the marginalized cultures themselves (BENJAMIN, 1994). Both thoughts, therefore, reflect interesting theoretical mechanisms for the contribution of a critical theory of human rights, in the name of respect for memory and not erasing stories.

Keywords: progress; decoloniality; critical theory of human rights.

Recebido em: 15/3/2021

Aceito em: 18/6/2021 


\title{
1 INTRODUÇÃO
}

\author{
"Many ingenious lovely things are gone \\ That seemed sheer miracle to the multitude".
}

(YEATS, 1928).

Em 1944 Jorge Luis Borges edita um dos seus mais renomados livros: Ficções. Nessa reunião de contos estão algumas de suas mais conhecidas obras, tais como: $\mathrm{O}$ jardim de veredas que se bifurcam; A biblioteca de Babel; Funes, o memorioso; O milagre secreto, etc. Esse volume traz também aquele que é um dos menores (em tamanho) contos de Borges, Tema do traidor e do herói. Como é esperado por quem se aventura na literatura de Borges, as poucas mais de cinco páginas desse conto são capazes de surpreender pela profundidade, pelas reviravoltas, pela inventividade e pelas inúmeras possibilidades que permite. Seu enredo traz a memória de um crime ocorrido no século 19 e que, analisado por especialistas no início do século 20, apresenta novas descobertas, uma nova história e a necessidade de decidir pela manutenção ou não do relato heroico que prevaleceu dessa história. Em dado momento, Borges afirma: "Que a história tivesse copiado a história já era suficientemente assombroso, que a história copie a literatura é inconcebível..." (BORGES, 2005, p. 139).

Essa provocação de Borges, sobre a necessidade de termos em conta o outro lado da narrativa dos fatos heroicos (mostrando que o papel de herói ou de traidor depende da versão da história que se conta), é uma espécie de versão literária para uma provocação teórica de Walter Benjamin que nos impõe a necessidade de "escovar a história a contrapelo" (sua tese VII, Sobre o conceito de História apud LÖWY, 2005, p. 70). Benjamin tinha uma preocupação muito sedimentada com as vítimas "invisíveis" da marcha da História. Conforme a lição de Reyes Mate, sua ênfase estava em impedir que essas vítimas tivessem uma segunda morte, além da morte física a morte da sua memória, da memória do seu sofrimento (MATE , 2011, p. 156).

Nesse sentido é que se impõe uma luta contra o esquecimento dessas vítimas e de suas dores, ou em outras palavras, que se estimule e se produza o pequeno relato, os fragmentos que se insurgem contra o esquecimento instaurando um outro saber que não esteja pautado na apologia, mas "na sua condição débil, como último reflexo de uma voz ausente" (NASClMENTO, 2009, p. 104). Na sua derradeira obra, "Sobre o Conceito da História" (1994), Benjamin apresenta uma reflexão crítica sobre a pretensão de uma linearidade histórica (rumo ao progresso). Nesse sentido, Benjamin irá pontuar uma crítica ante uma postura que considera o advento do futuro como necessariamente um progresso, advertindo, na linha do que já havia proposto Freud, em 1938: "vivemos em uma bem estranha época e constatamos com surpresa que o progresso se alia à barbárie" (FREUD, 1993, p. 68).

No texto do argentino Borges que trazemos no começo desse artigo, temos outra inspiração para nossa proposta: Borges traz na epígrafe um trecho de um poema clássico de $\mathrm{W}$. $\mathrm{B}$. Yeats, Nineteen Hundred and Nineteen, que foi escrito em 1928 como uma resposta às atrocidades cometidas pelos Black and Tans, ${ }^{1}$ na Irlanda. Nesse poema Yeats apresenta imagens do

Nome dado aos britânicos recrutados para exercer o policiamento na Irlanda depois da 1a Guerra Mundial e que eram conhecidos por sua violência e brutalidade, provocando muitas mortes em suas ações (BRITANNICA, 2020). 
passado em contraste com a crescente mortandade no (e do) mundo, apelando ao conceito de recorrência histórica e ao tema dos homens atuando segundo um "papel preconcebido" (BORGES CENTER, 2020). E se existe um fato que parece recorrente na história e um papel que parece "preconcebido" para um grande número de pessoas é o de vítima que sofre em silêncio sem receber o justo tratamento por seu sofrimento. A conexão dessas reflexões benjaminianas com o pensamento do filósofo, e conterrâneo de Borges, Enrique Dussel, parece clara na medida em que, para este último, os fundamentos que sustentaram a lógica da modernidade serviram, sem grandes críticas, como pano de fundo para a exploração colonial e o consequente apagamento histórico dos povos vencidos. É nesse sentido que Dussel enfatizará a necessidade de se recontar a história sob a ótica dos povos vencidos, colonizados, a fim de melhor entender sua dinâmica, cultura e sociedade, promovendo um resgate do que ficou soterrado por narrativas eurocêntricas (DUSSEL, 2005).

A partir desses elementos, este artigo objetiva uma apresentação da teoria da memória (BENJAMIN, 1994) que sirva de base epistemológica para uma abordagem crítica sobre os perenes efeitos da racionalidade colonizadora (DUSSEL, 2005). Essas chaves teóricas atuarão como fundamentos para se pensar em uma teoria crítica dos direitos humanos que dê conta de fazer justiça às vítimas que sofrem em silêncio, que seja capaz de promover a emancipação e liberação que seu projeto moderno promete, que possa, conforme Benjamin, estar apta para "colocar o real no lugar da ilusão" (BENJAMIN, 2016, p. 27).

\section{A VIOLÊNCIA COLONIZADORA NA HISTÓRIA ESCOVADA A CONTRAPELO: A Destruição da Memória}

Em um dos mais contundentes libelos contra o colonialismo Aimé Césaire é enfático em afirmar que a "Europa é indefensável" e nesse sentido é preciso conhecer a fundo o colonialismo para darmos conta de fazer um retrato mais fiel e adequado da figura do colonizador, pois sua mentalidade, sua brutalidade e opressão continuam vivas e atuantes. Nesse sentido, é lapidar seu sarcasmo em afirmar que o paradigma civilizatório que afirmou levar desenvolvimento e progresso aos povos "bárbaros" colonizados é o mesmo que nega a esses mesmos povos acesso aos mais básicos bens e serviços necessários a uma vida digna, tais como educação, saúde, segurança, saneamento, etc. (CÉSAIRE, 2020, p. 27).

Conforme o dicionário Houaiss, o verbo colonizar além de ter o sentido de criação de uma colônia ou de habitar como colono, no sentido figurado é definido como propagação, como invasão (GRANDE DICIONÁRIO HOUAISS, 2020). Importando essa definição léxica para uma análise social e histórica, é fácil perceber a adequação desse último sentido (figurado) com a realidade que marcou a expansão territorial europeia no início da modernidade (DUSSEL, 2015), com suas invasões armadas, que tomavam territórios, subjugando as civilizações residentes nesses locais antes da sua chegada. Nesse sentido, a perspectiva decolonial, que pretendemos utilizar neste artigo impõe ultrapassar a narrativa oficial do colonizador. Franz Fanon, em uma das mais clássicas obras sobre o pensamento decolonial, trata da questão da violência da colonização em um sentido em que o colonizador (ou colono, nos dizeres de Fanon) extrai desse processo a sua verdade, sua fábula de sucesso, além das suas riquezas materiais. Nesse sentido, ele afirma que "o colono e o colonizado [se] conhecem há muito tempo. E, na realidade, tem razão o colono quando diz conhecê-los. Foi o colono que fez e 
continua fazendo o colonizado. O colono tira a sua verdade, isto é, os seus bens, do sistema colonial" (FANON, 1961, p. 31).

O colonizador vale-se do seu poderio econômico, tecnológico, estratégico e das suas alianças políticas para promover invasões territoriais com intuitos exclusivamente econômicos nos territórios que apresentam potencial e atrativos para as demandas de momento dos mercados. É nesse sentido que se afirma que "os colonizadores operam sob diversas condições e configurações de um universo relacional de dominação europeia às demais populações globais" (LIMA; KOSOP, 2019, p. 2600). Tendo isso em conta, quando falamos de um processo violento, o foco não recai exclusivamente nas incursões bélicas do momento de invasão desses territórios, mas inclui a violência simbólica (BOURDIEU; PASSERON, 1992, p. 15 et seq.) da imposição de um novo modo de vida, de uma nova cultura, uma nova religião, uma nova epistemologia, que exigem em troca o apagamento daquela que foi colonizada. A história frequentemente explicitada nos mecanismos oficiais é fruto desse processo, produzida e disseminada do ponto de vista do colonizador, que impôs sua narrativa histórica. Não raro, o colonizador apresenta-se como um salvador da pátria, que traz melhorias e um desenvolvimento que jamais teriam se desenvolvido na comunidade originária daquele território.

Nesse mesmo sentido, Edward Said, na sua obra clássica "Orientalismo", é enfático em afirmar que aquilo que se conhece por Oriente foi criado à força pelo Ocidente colonizador e como consequência a condição de Oriente é fruto de julgamento, de estudos (como o de um corpo exótico), de disciplina. Em suma, aquilo que o colonizador define como sendo ilustrativo do que ele quer chamar de Oriente, de forma que Said propõe que se deve analisar o orientalismo como um exercício de força cultural. Ao evidenciar essa necessidade, ele acaba por chamar a atenção para a urgência de se interromper uma pretensão normativa e epistemológica que faz com o que "o Oriente e tudo o que havia nele era, se não patentemente inferior ao Ocidente, algo que necessitava de um estudo corretivo do Ocidente". Constitui o orientalismo, em resumo, tudo que reduz o Oriente aos campos disciplinares, judiciais, educacionais, tudo que o reduz à curiosidade e escrutínio, sob controle e delimitação de um governo (SAID, 2012, p. 74).

É facilmente perceptível, na contemporaneidade, que não se sustenta mais a lógica pela qual o modo de vida do colonizador europeu seja apresentado como o "correto". Isso porque resta cada vez mais clara a herança das culturas não europeias para os hábitos sociais contemporâneos. ${ }^{2} \mathrm{O}$ fato dessa influência da cultura não ocidental na realidade atual ter se tornado visível é consequência de lutas contra um longo processo de apagamento da história desses diversos povos violentados em um processo denominado por Paulo Freire de invasão cultural:

A invasão cultural tem uma dupla face. De um lado, é já dominação; de outro, é tática de dominação. Na verdade, toda dominação implica numa invasão, não apenas física, visível, mas às vezes camuflada, em que o invasor se apresenta como se fosse o amigo que ajuda. No fundo, a invasão é uma forma de dominar econômica e culturalmente ao invadido. In-

Facilmente perceptível: na onipresença da culinária japonesa em qualquer cidade de médio e grande porte ocidental; na origem chinesa de quase todos os produtos consumidos pelo Ocidente; mais recentemente, no sucesso da cultura pop sulcoreana (K-pop), etc. 
vasão realizada por uma sociedade matriz, metropolitana, numa sociedade dependente, ou invasão implícita na dominação de uma classe sobre a outra, numa mesma sociedade (FREIRE, 1987, p. 93).

A imposição do modo de vida do colonizador tem por objetivo não só apagar um modo de vida que ele considera indesejável, mas igualmente disseminar os próprios princípios como o único meio de vida correto, possível e aceitável, criando-se uma divisão entre "nós" e "os outros" e excluindo aqueles que resistem ao novo estilo de vida ou, por qualquer razão, não conseguem adaptar-se. A segregação do modo de vida do colonizado é uma ferramenta eficaz de invasão cultural, pois cria uma cultura marginal, "errada", indesejável, e gera nos próprios colonizados um desejo de abdicar da própria história e se aproximar do estilo de vida do colonizador, a fim de sair da margem. É nesse sentido que Fanon afirma a compartimentação do mundo colonial, em cidades europeias e indígenas, em escolas para os colonizadores diferentes das dos colonizados, como mostra de modo eloquente o exemplo histórico do apartheid na África do Sul (FANON, 1961, p. 32).

Em suma, podemos afirmar que o processo de colonização funda-se ao mesmo tempo em uma invasão física, bélica, territorial e, igualmente, em um processo de invasão cultural que apaga da História canônica e oficial a cultura e a subjetividade do colonizado, criando uma cultura que, quando não consegue ser integralmente suprimida, torna-se marginalizada. É sabido que, especialmente na época das grandes navegações, havia um legítimo desprezo pelos povos colonizados e sua cultura e seu estilo de vida eram considerados inferiores pelos colonizadores, que praticaram tanto genocídio e escravidão quanto uma destruição massiva de todo e qualquer registro de sua existência. Isso fica ainda mais evidente quando tratamos de povos que não tinham como cultura a produção de escritos ou construções majestosas, como os povos indígenas brasileiros. $\mathrm{O}$ que sabemos sobre eles é que existiram e foram exterminados, não havendo nenhuma preocupação em preservar sua memória. ${ }^{3}$ Devemos afirmar que a memória tem, como condição para sua formação, o testemunho dos seus sujeitos que ao narrarem o que passaram, ao lembrarem suas tradições familiares e comunitárias, constroem uma memória política que encara tudo o que permanece oculto ou longe da nossa compreensão e conhecimento (MOREIRA; GOMES, 2019, p. 371).

Assim, sem nenhuma preocupação com a preservação histórica, sem registros físicos, ou sem a cultura popular, diversas memórias podem ser apagadas da História. Nesse ponto, Turini (2004, p. 102) observa que:

Momento particularmente interessante para pensarmos sobre esta situação ocorreu nas "comemorações" em torno dos 500 anos do Brasil, em 2000. Na televisão, diariamente podia-se assistir à propaganda dos Correios "mostrando", através de uma sucessão de imagens como pano de fundo a leitura da carta de Caminha, como o país foi se "desenvolvendo" desde a chegada dos portugueses em 1500 até o que é hoje: um país na era da Internet, da globalização, do progresso.

\footnotetext{
Em 2 de setembro de 2018 ocorreu um grande incêndio no Museu Nacional, localizado na Quinta da Boa Vista, no Rio de Janeiro - Brasil, o qual contava com 200 anos de história e 20 milhões de itens em seu acervo, entre os quais se encontravam afrescos que sobreviveram à erupção que dizimou Pompeia, itens e artefatos de povos indígenas já extintos e de tribos africanas isoladas e/ou já extintas. Tais itens, ao se perderem para sempre, levaram consigo os únicos registros existentes de povos e civilizações que não mais existem (SANTOS, 2020).
} 
Os efeitos dessa perspectiva de apagamento e marginalização da história do "outro", do sujeito colonizado, permanecem na contemporaneidade quando, por exemplo, verificamos a omissão das histórias das vítimas da ditadura civil-militar brasileira. Assim como ocorre aos colonizados, impõe-se uma relação de dominação na qual um grupo detinha o poder em dizer a História, em determinar quais eventos seriam narrados e como o seriam. Guardadas as devidas proporções e diferenças, percebemos a permanência de uma lógica similar operando na formação narrativa, na qual os vencedores narram os fatos de acordo com sua melhor conveniência. ${ }^{4}$ Ouvimos histórias contadas pelos generais que ficaram no poder, ouvimos histórias sobre os revolucionários que representavam a luta contra a repressão, mas quantos outros relatos nunca ouvimos? Quantas pessoas "comuns" passaram por diversas atrocidades e não conseguiram sequer um lugar na memória?

O processo de colonização, sob essa análise, perpassa um processo de reescrita histórica, do apagamento de povos, culturas e de criação de uma narrativa que favorece aqueles que detêm o poder de dizer a História aos demais. Em se tratando desse exemplo do período ditatorial, ainda em comento, observa-se que aqueles que estavam no poder traziam para si o poder de determinar o que seria imortalizado e dito às próximas gerações e não havia ali uma preocupação em narrar os fatos como de fato ocorreram, mas de uma forma que beneficiasse os interesses de quem os contava.

O reflexo desse apagamento de identidade e dessa imposição de um modo de vida como correto inflige aos grupos vencidos uma marginalidade com reflexos não apenas no que respeita à memória, mas também na afirmação das imponentes desigualdades que costumam caracterizar esses territórios transformados em colônias. Por isso, sofrem as mazelas de uma sociedade que falha em fazer justiça às atrocidades pelas quais os grupos que têm suas memórias apagadas até hoje padecem:

Ou seja, o aclamado Estado (Liberal) Democrático de Direito não transforma a realidade construída historicamente, as desigualdades, as iniquidades e, muitas vezes, até mesmo as neutraliza e naturaliza, impedindo de tornar visíveis situações que, na aparência da normatividade, escondem as mazelas de uma sociedade fundada na exclusão, em particular, daquelas expressas pela questão racial, de regra intimamente conectada com a questão socioeconômica (MORAIS; MOREIRA, 2019, p. 21).

A partir do que foi anteriormente apresentado, veremos no próximo item como Walter Benjamin, enfaticamente, denuncia toda uma concepção de história que, agindo por uma "identificação com os vencedores" (que são os heróis ou gênios), consagra a visão desses últimos contra o exército dos vencidos e dos sem-nome: "os dominantes do momento são herdeiros de todos aqueles que venceram na história" (OLIVEIRA, 2017, p. 102). É nesse sentido que se afirma que o tribunal da História, caso exista, será sempre injusto, pois ele consagra os vencedores, excluindo os marginalizados e condenando os vencidos ao esquecimento. Isso fica ainda mais claro diante da constatação de que celebrar a cultura significa, consequentemente, privilegiar os vencedores em todas as circunstâncias, esquecendo-se, com isso, os serviçais e escravos sem os quais nada teria sido feito ou mereceria ser conservado (BOUGANIN, 2007, p. 158).

\footnotetext{
${ }^{4}$ Um texto excelente sobre o silenciamento provocado pela ditadura brasileira a suas vítimas é o "Os fuzis e as flechas", de Rubens Valente, que apresenta uma análise dos arquivos sobre a ditadura civil-militar brasileira buscando recuperar a história de lutas, resistências e perecimento dos indígenas brasileiros naqueles anos (VALENTE, 2017).
} 


\section{A CRÍTICA AO DISCURSO DO PROGRESSO E A CONSTANTE VIOLAÇÃO DE DIREITOS HUMANOS DOS POVOS COLONIZADOS}

Apesar de o momento histórico vivido por Walter Benjamin ter antecedido (e, em certo sentido, preparado as condições para) a luta anticolonialista, que passa a encontrar seu tempo no período pós-2a Guerra, sua inegável sensibilidade não deixou de ter em conta tão cruel realidade. Em uma curta resenha que escreveu para um livro sobre Bartolomeu de Las Casas, publicado no fim da década de 20, Benjamin constatava com horror que "la historia colonial de los pueblos europeus comienza con el escandaloso proceso de la Conquista, que convierte al mundo recién conquistado en una cámara de torturas" (BENJAMIN, 2020, p. 2100). Esse pequeno trecho deixa à mostra as mais marcantes características do pensamento benjaminiano, ou seja, uma preocupação obsessiva com as barbáries promovidas em nome do progresso, com o sofrimento mantido em silêncio, com uma política do esquecimento (em contraposição à sua proposta de uma memória política) que provocaram muito sofrimento e, numa lei do eterno retorno, continuam a provocar. Nos seus termos, Benjamin irá afirmar, nas notas preparatórias das suas famosas teses "Sobre o conceito de história", que três são os motivos que sustentam sua concepção da História: "A descontinuidade do tempo histórico; o poder destruidor da classe trabalhadora e a tradição dos oprimidos" ${ }^{5 \prime}$ (MISSAC, 1975, p. 44).

Para os propósitos deste artigo, sua crítica ao progresso mostra-se particularmente adequada, pois, pela perspectiva do autor, é possível afirmar que a Revolução Industrial, no século 19 , permitiu uma perniciosa ideia de progresso. Isso porque acreditava-se que o advento de uma economia moderna automatizada, escalonada e financeira, acarretaria por si só uma melhoria na qualidade de vida e na igualdade entre as pessoas. É óbvio que essa perspectiva foi recebida com esperança diante dos inegáveis avanços tecnológicos, provocando, contrário senso, uma rejeição a práticas sociais e modos de vida tradicionais e comunitários, que passariam a ser considerados atrasados.

Não há nada que tenha corrompido tanto o operariado alemão quanto a crença de que ele nadava com a correnteza. O desenvolvimento técnico parecia-lhe o declive da correnteza em cujo sentido acreditava nadar. Daí era um só passo até a ilusão de que o trabaIho fabril, que se inserisse no sulco do progresso técnico, representaria um feito político (BENJAMIN. 1992, p. 163).

Esses avanços tecnológicos e industriais disfarçavam uma severa exploração do trabaIhador que fomentava desigualdades sociais e a massificação da cultura. Nesse sentido, Benjamin é enfático em afirmar, na famosa alegoria do "Angelus Novus" da sua tese IX, que aquilo que chamamos de progresso é algo que nos empurra para o futuro e nos torna incapazes de ser reverentes aos "escombros" humanos que se acumulam com sua passagem (LÖWY, 2005, p. 87). Em contrapartida a essa preocupação benjaminiana, a visão até hoje predominante é que a História caminha sempre em direção a uma evolução constante, o presente sempre detém uma superioridade ao passado e os avanços tecnológicos da época passaram a reforçar essa postura, duramente criticada por Benjamin. Turini (2004, p. 98), nesse particular, observa que

"La discontinuité du temps historique; le pouvoir destructeur de la classe ouvrière; la tradition des opprimés". 
[...] o tempo da história é identificado como o tempo da evolução e esta como sinônimo de progresso. Por essa linha de interpretação, o presente é sempre a etapa que avança para o melhor, em relação a um passado visto como ultrapassado, atrasado. Coloca-se, então, a perspectiva de que a humanidade evolui inexoravelmente para um fim "superior" ou "adiantado".

No seu derradeiro texto, Benjamin resume uma preocupação que sempre o acompanhou e que se contrapunha fortemente ao conceito de História como um evento linear que sempre caminhava em direção ao avanço e ao progresso como um fruto de posturas que defendiam o trabalho como fonte da moral e lisura. Nesse sentido, Benjamin entendia que a História que estava sendo escrita não contava com exatidão sobre o sofrimento dos povos, à custa dos quais o malfadado progresso estava sendo construído. Para ele caberia, então, ao historiador "escovar a história a contrapelo", permitindo-se adotar um novo olhar sobre leituras de documentos históricos, novas interpretações sobre fatos, traçando um diálogo aberto entre presente e passado e possibilitando um entendimento mais amplo e diverso da História. Tal proposta, assim, visava a romper com os conceitos clássicos e lineares de uma História progressista, que sempre rumaria para evoluções, quando o novo, o futuro, sempre representaria, automaticamente, algo supostamente melhor e mais avançado. Como panaceia para essa insensível narrativa que continua a provocar dores e sofrimentos que permanecem em silêncio, impõe-se ter a empatia como método de construção que permite um tratamento adequado para as vítimas dessa marcha histórica (BENJAMIN, 1994, p. 225).

Um dos maiores especialistas na obra de Benjamin, Michael Löwy afirma que esse escovar a história a contrapelo impõe considerá-la sob a perspectiva dos derrotados, excluídos, dos vencidos. E nesse sentido, pontua:

Por exemplo, a rica cultura do Segundo Império francês deve ser analisada [...] levando em conta a derrota dos operários em junho de 1848 e a repressão ao movimento revolucionário [...] que ela provocou durante várias décadas. Da mesma maneira, a brilhante cultura de Weimar deve ser comparada à situação dos desempregados. Dos pobres e das vítimas da inflação - como em Rua de mão única. Em outras palavras, para citar uma das notas preparatórias, a história da cultura "deve ser integrada à história da luta de classes" (LÖWY, 2005, p. 79).

Como afirmado desde o princípio deste tópico, ao assumir essa perspectiva Benjamin rompia com uma concepção linear de História, admitindo que o futuro não representaria por si só um progresso e nem tudo que fosse considerado progresso para uns representaria necessariamente melhoria para todos. Pregando, dessa forma, a necessidade de uma empatia, de uma pesquisa aprofundada que admita que o mesmo fato histórico ao mesmo tempo significa inúmeras vitórias e desenvolvimento para uns e inegáveis sofrimentos e opressão para outros, gerando, assim, um dever de memória para com as "vítimas do progresso". Nesse sentido, ter memória e fazer justiça às vítimas do passado e às que até hoje sofrem nessa busca por progresso e desenvolvimento. Ao se fazer/ter memória define-se um marco (histórico e geográfico), mas ao mesmo tempo se mantém em aberto as infinitas possiblidades não contempladas que permitirão sempre a escrita de uma nova História (OLIVEIRA, 2017, p. 160).

É nesse sentido que Fanon (1961, p. 94) afirmará que "o bem-estar e o progresso da Europa foram construídos com o suor e os cadáveres dos negros, dos árabes, dos índios e dos 
amarelos. Isso, nós decidimos não esquecer". Em outros termos, resta claro que o malfadado progresso dos vencedores é geralmente construído à custa do sofrimento dos outros povos, ainda que esse custo seja posteriormente relativizado ou silenciado pela narrativa geral. Nas palavras de Benjamin, impõe-se que o papel do historiador deixe de ser apenas aquele de um pesquisador que se limita a contar os fatos como retratados, para passar a considerar todas as dinâmicas éticas, sociológicas e culturais, isso incluindo todos os envolvidos na equação histórica e as respectivas contribuições para os desfechos dos respectivos eventos.

O historicismo se contenta em estabelecer um nexo causal entre vários momentos da história. Mas nenhum fato, meramente por ser causa, é só por isso um fato histórico. Ele se transforma em fato histórico postumamente, graças a acontecimentos que podem estar dele separados por milênios. O historiador consciente disso renuncia a desfiar entre os dedos os acontecimentos, como as contas de um rosário. Ele capta a configuração, em que sua própria época entrou em contato com uma época anterior, perfeitamente determinada. Com isso, ele funda um conceito do presente como um "agora" no qual se infiltraram estilhaços do messiânico (BENJAMIN, 1994, p. 232).

Exercitar o papel da empatia no estudo da História permite-nos uma visão mais crítica do progresso, assim como possibilita entender que a história nem sempre caminha para um desenvolvimento, admitindo-se que involuções podem acontecer durante esse processo histórico. Mais uma vez aqui, suas contundentes palavras construídas com a alegoria do "Angelus Novus" em sua Tese IX, são claras ao enfatizar que:

O anjo da história deve ter esse aspecto. Seu rosto está dirigido para o passado. Onde nós vemos uma cadeia de acontecimentos, ele vê uma catástrofe única, que acumula incansavelmente ruína sobre ruína e as dispersa a nossos pés. Ele gostaria de deter-se para acordar os mortos e juntar os fragmentos. Mas uma tempestade sopra do paraíso e prende-se a suas asas com tanta força que ele não pode mais fechá-las. Essa tempestade o impele irresistivelmente para o futuro, ao qual ele vira as costas, enquanto o amontoado de ruínas cresce até o céu. Essa tempestade é o que chamamos de progresso (BENJAMIN, 1994, p. 226).

É necessário ressaltar, por fim, que o autor não prega uma visão saudosista e anacrônica da realidade, afinal é notório o trabalho de Benjamin sobre alguns dos mais avançados progressos tecnológicos do começo do século 20 , sobretudo os relacionados às artes (tais como a fotografia, o cinema, a arte contemporânea, a mudança na perspectiva literária do romance, assim como seus textos sobre os avanços tecnológicos vivenciados a partir da $1^{\text {a }}$ Grande Guerra). Apesar disso, ele mantém sua postura crítica quanto à aceitação inerte daquilo que se vende como progresso, daquilo que se apresenta como a salvação em um futuro idílico, mas que ao mesmo tempo se mostra insensível para as consequências que provoca e que, muitas vezes, nem se dá conta. Nesse sentido, Turini explica que a crítica ao progresso é fundamental na perspectiva de Benjamin, e essa crítica não é motivada por um anacronismo saudosista sobre um tempo que passou, mas sim visando a colaborar para o surgimento de novas possibilidades de vida social (TURINI, 2004, p. 112).

Com essa última mensagem vislumbramos um interessante paralelo entre a teoria de memória e a crítica ao progresso de Walter Benjamin com as bases teóricas sobre decolonialidade de Enrique Dussel, em especial quando esse último, assim como Benjamin, questiona a 
perspectiva de um conceito único e generalizado de progresso, da História, da epistemologia, da normatividade, etc.

\section{APROXIMAÇÕES ENTRE A CRÍTICA DO PROGRESSO E A VISÃO DECOLONIAL: Bases Para Reflexões Humanistas na América Latina}

O filósofo argentino, radicado no México há mais de 40 anos, Enrique Dussel, instiga-nos a questionar a nossa própria história, na condição de "ex-colônias", numa proposta que muito se aproxima do "escovar a história a contrapelo", de Benjamin. Nesse sentido, ele afirma que desde as primeiras conquistas e massacres que marcaram o início do período colonial esteve presente uma racionalidade (epistemologia) moderna e eurocêntrica que provoca o reconhecimento dos colonizadores como sujeitos privilegiados para se contar essa história, tendo na sua "visão de mundo" o cerne daquela narrativa que se fez oficial. Diante disso, Dussel irá propor uma outra história crítica desse projeto da modernidade europeia, história contada sob a perspectiva dos povos colonizados e, para tanto, deve-se enxergar a origem da modernidade com "novos olhos", ou seja, impõe-se a releitura dessa história por um "observador externo". Percebe-se aqui uma necessidade de se desprender da narrativa europeia como meio privilegiado de se enxergar a história das colônias, deve-se questionar "que direito a Europa tem de dominar colonialmente as Índias?" (DUSSEL, 2015, p. 38).

Essa proposta de Dussel oferece um contraponto à ideia do colonizador de que a civilização colonizada encontra-se em atraso e por ela faz um bem ao invadir sua cultura e levar o "progresso". Ou seja, como se houvesse uma razão dada a posteriori que justificasse todas os "efeitos colaterais" do empreendimento colonial. Nesse sentido, o pensamento de Angela Davis, por sua vez, reforça o viés crítico dessa ideia de que o vencedor, o colonizador, o invasor cultural têm sobre si a visão de salvador do colonizado, que trouxe consigo o progresso, a civilização, um modo de vida "melhor" e mais "evoluído", ao relembrar que, "em 1918, quando o influente acadêmico Ulrich B. Phillips declarou que a escravidão no Velho Sul imprimiu o glorioso selo da civilização nos africanos selvagens e em seus descendentes nascidos nos Estados Unidos, ele lançou as bases para um longo e acalorado debate" (DAVIS, 2016, p. 22). Nesse sentido é que Turini afirma:

Mesmo entre professores e alunos, muitas vezes houve - e há - no balanço dos 500 anos, uma certa compreensão de que a "descoberta" dos portugueses, apesar de toda a violência da colonização, possibilitou a entrada do Brasil no "mundo civilizado". E, nesse processo, a ação dos bandeirantes aparece como fundamental, mesmo que se reconheça os seus métodos como violentos, cruéis, sanguinários. Afinal, sem eles, o país terminaria em São Paulo... (TURINI, 2004, p. 102).

Em outros termos, podemos afirmar que os colonizadores sequer consideram a história e a cultura da civilização invadida como algo digno de ser narrado e tornado conhecido. A preservação e o legado dessas passam a ser relativizados diante do progresso que, inevitavelmente, o projeto da modernidade levaria, mesmo com o custo das inúmeras atrocidades físicas, morais e sociais. Dussel entende que a resposta para a pergunta formulada sobre o direito que a Europa teria de invadir outros territórios é tautológica, a ponto de acarretar no fato de que "a Modernidade nunca mais se perguntará existencial nem filosoficamente por este direito à dominação da periferia até o presente" (DUSSEL, 2015b, p. 39), Mostrando-se 
natural concluir que a contrapartida para as promessas da modernidade e do progresso não justifica o apagamento da história e da cultura dos povos colonizados.

Os exemplos para o que antes apresentamos são claros quando observamos que, desde seu início, "no século XVI, a retórica salvacionista da modernidade enfatizava a conversão ao cristianismo", nas missões religiosas que convertiam forçadamente povos indígenas, batismos de povos negros escravizados, entre outras práticas que consideravam suas culturas como primitivas, atrasadas e uma conversão religiosa e o apagamento das vivências dos povos convertidos representavam um progresso, uma "salvação" (MIGNOLO, 2008, p. 273).

Quando tem seu ponto de vista tomado como cerne da narrativa, os vencedores apropriam-se da História e, consequentemente, da verdade a ser contada. São também os donos e, por vezes, os produtores dos registros históricos, de forma a decidir o que e como neles constam. Não raro são vistos como heróis, salvadores, detentores do progresso, exceto por aqueles que trazem consigo a lembrança da opressão.

Segundo Dussel, a subjetividade do dominador torna-se a própria História. Nas suas palavras:

Porque a experiência originária da FL consiste em descobrir o "fato" massivo da dominação, do constituir-se de uma subjetividade como "senhor" de outra subjetividade, no plano mundial (desde o começo da expansão europeia em 1492 - fato constitutivo originário da "Modernidade") Centro-Periferia; no plano nacional (elites-massas, burguesia nacional - classe operária e povo); no plano erótico (homem - mulher); no plano pedagógico (cultura imperial elitista versus cultura periférica popular, etc.); no plano religioso (o fetichismo em todos os níveis); no nível racial (a discriminação das raças não-brancas), etc. [...] O pobre, o dominado, o índio massacrado, o negro escravo, o asiático da guerra do ópio, o judeu nos campos de concentração, a mulher objeto sexual, a criança sob a manipulação ideológica [...] não podem partir simplesmente da "estima de si mesmo" [...]. A anterioridade do Outro que interpela constitui a possibilidade do "mundo" ou de si mesmo como reflexivamente valiosa [...]. Não se fala aqui que, necessariamente, os vencedores são vilões e invasores, pois, obviamente, em sua ótica, possuem uma justificativa para seus atos. Igualmente, nas interações humanas não se pode enxergar uma dualidade cinematográfica simplista de vilão/mocinho. Mas, ao mesmo tempo, necessária se faz uma atenção à memória daqueles que foram vencidos para uma total compreensão social da cultura e sociedade atual (DUSSEL, 1998, p. 20).

Segundo Oliveira e Gomes (2017, p. 82-83), torna-se necessário "reconhecer o risco político e social que se corre quando o trabalho de memória e reconstrução histórica de uma nação não é preservado [...] pois é do esquecimento que se permite a reescrita da história, mas uma reescrita desvirtuada, desprendida da verdade fatual que originou a história". Tal risco é perceptível quando se fala de povos escravizados. Mais uma vez aqui, Angela Davis é didática ao tratar da questão das mulheres negras escravizadas, que tiveram sua dinâmica pessoal e familiar apagada da História, criando-se uma mística a seu respeito que não condiz com a realidade. Não raro, as mulheres escravizadas eram tratadas apenas como matriarcas, "parideiras", sendo altamente sexualizadas e tendo sua realidade e dignidade relegadas ao apagamento histórico. 
Em meio a toda essa atividade intelectual, porém, a situação específica das mulheres escravas permanecia incompreendida. As discussões incessantes sobre sua "promiscuidade sexual" ou seus pendores "matriarcais" obscureciam, mais do que iluminavam, a situação das mulheres negras durante a escravidão. Herbert Aptheker continua sendo um dos poucos historiadores a tentar criar um alicerce mais realista para a compreensão da muIher escrava (DAVIS, 2016, p. 22).

Era fundamental, portanto, para o colonizador, via de regra, considerar o estilo de vida e a cultura nas colônias como algo inferior, e para isso sequer considerava os povos colonizados como civilizados, razão pela qual não houve nenhuma preocupação em preservar sua cultura, notas, compreender seu estilo de vida ou até mesmo manter registros de sua existência. Quando se permite esquecer as narrativas dos povos que integraram um processo histórico, incorre-se no sério risco de ter sua cultura e singularidades apagadas e preenchidas pelo imaginário popular, assim como criar uma mística que os reproduza como vilões, ou como povos não civilizados que precisavam da intervenção do colonizador para se desenvolver. Esse processo de desumanização começa com a qualificação dessas culturas e povos como algo negativo que possibilita seu apagamento histórico e reforça o modo de vida instituído pelo colonizador como o correto, o inovador, o progressista. Com o tempo, deixa-se de enxergar a população vencida como seres humanos que tiveram seu modo de vida invadido e dizimado (MOREIRA; MOREIRA JUNIOR, 2017, p. 291).

Resgatar tal memória (e empenhar-se em mantê-la) consiste em justiça aos descendentes dos povos vencidos, cujo direito à memória e subjetividade em muito se entrelaça com o próprio direito à identidade. Nesse sentido, é essencial ter em consideração que memória, testemunho e narrativa devem atuar harmonicamente, uma vez que o testemunho alimenta a narrativa, enquanto essa última reaviva a memória. A memória sendo novamente viva passa a ser parte do imaginário daquela comunidade política. É nesse sentido que podemos afirmar que "a memória pertence ao passado, mas seus reflexos são sentidos no presente, e serão fundamentais ao futuro, seja ele qual for" (MOREIRA; GOMES, 2019, p. 379).

$O$ resgate da memória pela ótica daqueles que foram vencidos tem um poder libertador de minimizar opressões cotidianas sofridas por aqueles que não se encontram no lado dominante, sanando a referida dualidade vilão/mocinho que redesenha a História, retratando os vencidos como bárbaros, errados, que merecem ocupar uma posição de menor destaque. "O projeto democrático é indispensável para que processos inclusivos e emancipatórios se realizem" (LUCAS, 2019, p. 5).

Aquele que opera ético-criticamente deve (está obrigado a) libertar a vítima, como participante (por "situação" ou por "posição" - diria Gramsci) da própria comunidade a que pertence a vítima, por meio de (a) uma transformação factível dos momentos que causam a negatividade material (impedem algum aspecto da reprodução da vida) ou discursivo-formal (alguma simetria ou exclusão da participação) da vítima; e (b) a construção, através de mediações com factibilidade estratégico-instrumental críticas, de novas normas, ações, microestruturas, instituições ou até sistemas completos de eticidade onde essas vítimas possam viver, sendo participantes iguais e plenos (DUSSEL, 2002, p. 265). 
Emerge, então, um dever ético de "libertar" as vítimas e/ou os vencidos do limbo histórico, aproximando a nossa narrativa de uma pesquisa abrangente que retrate todos os lados envolvidos nos eventos históricos, e não apenas aqueles que desses eventos saíram vencedores. Diante disso, o que se pretende é termos em conta a possibilidade de concebermos também novas concepções do sujeito que se diferenciem daquele indivíduo idealizado pela Europa burguesa, ou seja, deve-se ter em conta a existência "de outros 'eu' sugeridos por uma nova gramática de pertencimento e acolhimento num plano de ressignificação das alteridades perdidas" (HOFFMAN; MORAIS; ROMAGUERA, 2019, p. 256).

Esse dever ético para com as vítimas do esquecimento consiste em fornecer uma narrativa histórica realista que os inclua e na qual elas não sejam apenas os descendentes dos vencidos que colhem os frutos dessa derrota, mas ao contrário, que os faça sujeitos e narradores da própria história. Dussel menciona um princípio da libertação, que impõe a promoção de uma transformação que seja levada a cabo pela própria comunidade das vítimas, sendo sua responsabilidade contar suas histórias e dores. Esse princípio "se origina prático-materialmente como normatividade a partir da existência de certo poder ou capacidade (o ser) na dita vítima" (DUSSEL, 2002, p. 559).

Em outro momento, afirma que se deve levar em conta

[...] a realização prática positiva, ou a práxis da libertação propriamente dita, tem sempre por sujeito sócio-histórico próprio de referência a própria comunidade crítica das vítimas - seja qual for o rosto com que se revele - e está sempre a cargo da responsabilidade da própria comunidade das vítimas: é um ato de autolibertação de um sujeito histórico específico (DUSSEL, 2002, p. 265).

No entendimento do autor, dessa forma, o resgate de registros históricos e uma releitura deles sob a ótica dos vencidos tornam-se uma questão de libertação dos povos das amarras, costumes e cultura que foram impostos pelo invasor. Tal resgate significa a recuperação de toda uma narrativa e de uma revisitação ao passado, de forma que ele seja recontado, incluindo as dinâmicas propositalmente excluídas. Torna-se uma questão de recuperar a dignidade dos povos, conhecer suas raízes e se desfazer da marginalização das culturas preexistentes nas colônias. Essa crítica a um modelo ético hegemônico leva à constatação da existência das vítimas, evidencia a falsidade desse modelo, ao mesmo tempo que deixa claro a ausência da participação das vítimas nos processos decisórios, o que torna frágil a pretensão da formação dos consensos pretendidos pelo sistema ético dominante (CALDAS, COZERO, 2020, p. 6).

O que se observa atualmente é que o direito à memória e ao resgate das próprias raízes trata de um direito inerente aos direitos de personalidade, de um direito e garantia fundamental intrinsecamente ligado à democracia e direitos humanos. A existência de uma memória, de uma cultura e de uma história coletiva está intrinsecamente ligada à formação individual de uma identidade. $\mathrm{O}$ indivíduo desenvolve seus valores baseado nas instruções sociais que recebe no modo de vida e da sociedade em que está inserido, de modo que "a identidade do ser humano depende, portanto, da sua adesão a um determinado complexo de bens, que não são (pré)dados, mas hermeneuticamente construídos (desvelados) a partir de uma determinada facticidade e historicidade" (Moreira, 2010, p. 22) Nas palavras de Bedin e Tosi (2018, p. 299) quando se fala de direitos humanos "o pluralismo ideológico é a 
base de uma formação que respeite os outros, as diferenças", de maneira a ser necessária a defesa de tal pluralismo como forma de se garantir a dignidade e a identidade de todos os povos.

Embora atualmente muito se fale em globalização e na criação de uma suposta "aldeia global", igualmente muito se tem falado em uma preservação de culturas, de modos de vida, de registros históricos e em uma tentativa de resgate do que foi perdido. É impossível falar em direito à memória sem falar em direitos humanos, em direito a uma identidade, a uma relação íntima com a própria cultura e com o próprio passado. "Não que o problema do multiculturalismo seja algo novo. É apenas uma realidade que se percebeu de forma mais substancial com o processo global de produção, operado a um só tempo, da sociabilidade e da barbárie" (LUCAS, 2013, p. 34)

Por essa razão a conexão entre as ideias de Walter Benjamin e Enrique Dussel são complementares e elucidativas. A teoria de uma memória crítica ao progresso, proposta por Benjamin, expõe que não é necessária a relação entre o que o progresso e a modernidade prometem e aquilo que provocam em termos de custos humanos naqueles que devem promover seus ideais. Nesse sentido, quando ele fala em "escovar a história a contrapelo", traz uma necessidade de se recontar o passado trazendo à luz todos os "escombros", todas as mazelas a que foram submetidos os povos eternamente vencidos na História. Já Dussel fala de uma libertação dos povos por meio de um resgate histórico daquilo que restou apagado, em termos benjaminianos de uma memória dos vencidos e colonizados, como uma forma de se desprender de um processo colonizador violento que dizimou fisicamente seus antepassados e que segue em um processo de apagamento da reminiscência desses diversos grupos.

\section{CONSIDERAÇÕES FINAIS}

Mesmo que as produções intelectuais de Walter Benjamin e Enrique Dussel não sejam contemporâneas, elas guardam inegáveis paralelos, que podem, em certo sentido, ser resumidos numa preocupação absoluta em se recuperar a narrativa histórica em favor dos vencidos e colonizados, ou seja, que haja a possibilidade de uma nova história que seja coerente com os sofrimentos passados e nos torne atentos para aqueles que continuam presentes.

Por um lado, Benjamin apresenta uma teoria da memória política que é crítica à ideologia do progresso e que se opõe fortemente à pretensão da sua época em conceber uma linearidade histórica, rumo a um futuro que por si só traria o progresso e melhoria natural para a vida de todos. Tal postura implicava uma arrogância que fazia o presente ser visto sempre como algo superior ao passado, sendo essa marcha histórica de constante evolução algo inescapável e necessário. Ao se opor de modo enfático a essa perspectiva, Benjamin entendia que tudo aquilo que se apresentava como progresso tinha um preço, quase sempre pago por povos marginalizados, que viam aquilo que chamavam de progresso como a materialização explícita do que se conhece como barbárie. É nesse sentido que ele nos convida a "escovar a história a contrapelo", desprendendo-se da narrativa oficial e observando todos os ângulos de todos os envolvidos no processo histórico.

Já Dussel mostra uma perspectiva similar à de Benjamin, com foco especial no estudo histórico dos efeitos da ideologia ocidental moderna, sobretudo na América Latina. O autor entende que a modernidade (ou progresso) supostamente trazida pelo colonizador não justi- 
fica de modo algum seus efeitos colaterais deletérios provocados por toda exploração e toda invasão sofrida pelos povos colonizados. Para o autor, a história contada pelo colonizador era uma fábula, em que o povo colonizado era primitivo em sua cultura e foi "salvo" pela modernidade trazida pelo colonizador. Nesse sentido, ele irá questionar as ações tomadas no período colonial, endossando a necessidade de um resgate da memória dos povos colonizados, a fim de resgatar sua humanidade, cultura e de o povo colonizado estabelecer raízes com a sua ancestralidade roubada no processo colonial.

A necessidade de resgate à memória dos vencidos tem valor histórico não apenas para fins arqueológicos e de registro, mas para recontar, de maneira justa, a História da própria humanidade como um todo. Quando se permite que apenas os vencedores tenham o poder de determinar o que será dito na História e sua ótica torne-se a narrativa central, incorre-se no risco de registrar e contar a História de forma ficcional, em que há vilões e mocinhos e sempre os vencidos serão os vilões. $\mathrm{O}$ apego insistente à visão histórica exclusiva dos vencedores traz enormes riscos à vida social, visto que cria culturas marginalizadas, indesejáveis, "erradas", legitimando a possibilidade de seu extermínio. Resgatar a memória dos vencidos, desapegando-se dos desígnios de progresso e modernidade, possibilita-nos uma análise mais ampla das dinâmicas sociais vigentes: permite-nos uma compreensão mais justa e equânime do presente, igualmente se constituindo em uma questão de dignidade.

No conto de Borges que trazemos na introdução desse texto, o personagem principal, ao se deparar com a possibilidade de uma nova narrativa para um fato histórico clássico se vê na necessidade de decidir entre manter o relato vigente e dominante ou revelar os novos detalhes que implicariam uma nova realidade. É essa escolha que também devemos fazer em favor de uma nova História, coerente e justa com os sofrimentos acumulados, reverente com seus autores e atores e, sobretudo, capaz de promover uma memória viva e narrada pelos vencidos sobre suas dores e suas heranças. Parafraseando os versos de Yeats que trazemos como epígrafe devemos reconhecer que muitas coisas apaixonantes e engenhosas se perderam e a possibilidade de que pudessem ser recontadas parecia um "milagre para a multidão".

\section{REFERÊNCIAS}

BEDIN, G.; TOSI, G. Direitos humanos: uma conquista civilizatória. Revista Direitos Humanos e Democracia, 6(12), p. 297-301, 2018. Disponível em: https://doi.org/10.21527/2317-5389.2018.12.297-301.

BENJAMIN, Walter. História da literatura e ciência da literatura. Rio de Janeiro: 7 Letras, 2016.

BENJAMIN, Walter. Marcel Brion, Bartolomé de Las Casas. "Padre de los índios". Revista Direito e Práxis, Rio de Janeiro, v. 11, n. 3, p. 2.099-2.101, 2020.

BENJAMIN, Walter. Sobre o conceito de história. In: BENJAMIN, Walter. Obras escolhidas. magia e técnica: ensaios sobre literatura e história da cultura. Trad. Sergio Paulo Rouanet. São Paulo: Brasiliense, 1994.

BENJAMIN, Walter. Teses sobre o conceito de história. In: BENJAMIN, Walter. Sobre arte, técnica, linguagem e política. Trad. Maria Luz Moita, Maria Amélia Cruz e Manuel Alberto. Prefácio Theodor Adorno. Lisboa: Antropos, 1992.

BORGES CENTER. The Tower. University of Pittsburgh. Disponível em: https://www.borges.pitt.edu/i/tower. Acessado em 30 de set. de 2020.

BORGES, Jorge Luis: Ficções. Rio de Janeiro: Editora Globo, 2005.

BOUGANIN, Ami. Walter Benjamin: le rêve de vivre. Paris: Albin Michel, 2007.

BOURDIEU, Pierre; PASSERON, Jean-Claude. A reprodução: elementos para uma teoria do sistema de ensino. 3. ed. Rio de Janeiro: Livraria Francisco Alves Editora, 1992. 
BRITANNICA. Black and Tan. Disponível em: https://www.britannica.com/topic/Black-and-Tan. Acesso em: 5 out. 2020.

CALDAS, Josiane; COZERO, Paula Talita. Voz das vítimas: a discursividade crítica em Dussel e o mecanismo de consulta da Convenção no 169 da OIT. Revista Direito e Práxis, Rio de Janeiro, 2020. Disponível em: https:// www.scielo.br/j/rdp/a/RjkgJRYvvkfK3JjCsXBgKtb/?lang=pt. Acesso em: 30 jul. 2020. DOI: 10.1590/21798966/2020/48706

CÉSAIRE, Aimé. Discurso sobre colonialismo. São Paulo: Veneta, 2020.

DAVIS, Angela. Mulheres, raça e classe. São Paulo: Boitempo, 2016.

DUSSEL, Enrique. En búsqueda del sentido (origen y desarrollo de una filosofia de la liberación). Anthropos, n. 180,1998

DUSSEL, Enrique. Ética da Libertação: na idade da globalização e da exclusão. Petrópolis: Vozes, 2002.

DUSSEL, Enrique. 1413-4675. Filosofazer, Passo Fundo, v. 47, n. 2, p. 11-44, 2015a. Semestral.

DUSSEL, Enrique. Europa, modernidade e eurocentrismo. Buenos Aires: Clacso - Consejo Latino Americano de Ciencias Sociales, 2005.

DUSSEL, Enrique. Filosofia de la Liberación. México: FCE, 2011.

DUSSEL, Enrique. Meditaciones anti-cartesianas: sobre el origen del anti-discurso filosófico de la modernidad. Revista Filosofazer, n. 46, ano 15, Passo Fundo, 2015b.

FANON, Frantz. Os condenados da Terra. Lisboa: Ulisseia llimitada, 1961.

FREIRE, Paulo. Pedagogia do oprimido. 17. ed. Rio de Janeiro: Paz e Terra, 1987.

FREUD, Sigmund: L'Homme Moïse et la religion monotheíste. Paris: Gallimard, 1993.

GRANDE DICIONÁRIO HOUAISS. Colonizar. Disponível em: https://houaiss.uol.com.br/corporativo/apps/uol_ www/v5-4/html/index.php\#1. Acesso em: 5 out. 2020.

HOFFMAM, Fernando; MORAIS, Jose Luis Bolzan de; ROMAGUERA, Daniel Carneiro Leão. Direitos humanos na sociedade contemporânea: neoliberalismo e (pós)modernidade. Revista Direito e Práxis, v. 10, n. 1, p. 250-273, mar. 2019. Fap Unifesp (Scielo). DOI: http://dx.doi.org/10.1590/2179-8966/2018/30740

LIMA, José Edmilson de Souza; KOSOP, Roberto José Covaia. Giro decolonial e o direito: para além de amarras coloniais. Revista Direito e Práxis, v. 10, n. 4, p. 2.596-2.619, dez. 2019. Fap Unifesp (Scielo). DOI: http://dx.doi. org/10.1590/2179-8966/2018/34117

LÖWY, Michael. Walter Benjamin: aviso de incêndio. Uma leitura das teses "Sobre o conceito de História". São Paulo: Boitempo, 2005.

LUCAS, Doglas Cesar. Os direitos humanos como mínimo ético para o diálogo intercultural. Revista Direito em Debate, 14 (24), 2013. DOI: https://doi.org/10.21527/2176-6622.2005.24.\%p

LUCAS, Doglas Cesar. Apresentação. Revista Direitos Humanos e Democracia, 7 (14), p. 5-6. 2019. DOI: https:// doi.org/10.21527/2317-5389.2019.14.5-6

MATE, Reyes. Meia noite na história: Comentários às teses de Walter Benjamin "Sobre o Conceito de História". Tradução Nélio Schneider. São Leopoldo, RS: Unisinos, 2011.

MIGNOLO, Walter D. Novas reflexões sobre ideia da América Latina: a direita, a esquerda e a opção descolonial. Caderno $C R H$, v. 21, n. 53, p. 239-252, mayo-agosto 2008.

MISSAC, Pierre. L'Ange et l'automate: notes sur les "Thèses sur le concept d'histoire". In: Les Nouveaux Cahiers, Paris, n. 41, p. 43-52, 1975.

MORAIS, José Luis Bolzan de; MOREIRA, Nelson Camatta. Constitucionalismo, Estado de direito e a invisibilidade social que "teima" em continuar. Revista de Direitos e Garantias Fundamentais, Vitória, v. 20, ed. 3, p. 11-30, set./dez. 2019.

MOREIRA, Nelson Camatta. A filosofia política de Charles Taylor e a política constitucional de Pablo Lucas Verdú: pressupostos para a construção do sujeito constitucional. Revista de Direitos e Garantias Fundamentais, Vitória, ed. 8, p. 15-54, 2010.

MOREIRA, Nelson Camatta; GOMES, Raoni Vieira. O julgamento da ADPF 153 pelo STF à luz da filosofia da memória política: narrar os fatos, juntar os trapos e lembrar para não esquecer. Revista Brasileira de Estudos Políticos, n. 119, p. 363-396, nov. 2019.

MOREIRA, Nelson Camatta; MOREIRA JÚNIOR, Ronaldo Felix. Os replicantes de nosso tempo - a violência estatal e a negação da igualdade e dignidade humana a partir da perspectiva da teoria crítica e da distopia na ficção científica. Revista Brasileira de Direito, v. 13, n. 3, p. 277-294, 22 dez. 2017.

NASCIMENTO, Lyslei. Borges e outros rabinos. Belo Horizonte: Editora UFMG, 2009. 
OLIVEIRA, Antonio Leal de. O direito à memória como um dos fundamentos da dignidade humana: memória política e a justiça para as vítimas do progresso. 2017. Tese (Doutorado) - PUC, Departamento de Direito, Rio de Janeiro, 2017. Disponível em: https://www.maxwell.vrac.puc-rio.br/32034/32034.PDF. Acesso em: 23 mar. 2019. OLIVEIRA, Antonio Leal de; GOMES, Raoni Vieira. Seletividade racial no sistema penal brasileiro: apontamentos para a reconstrução da memória racial nacional a partir das teses de Walter Benjamin. Revista Brasileira de Ciências Criminais, São Paulo: RT, v. 135, 2017.

SAID, Edward. Orientalismo: o Oriente como invenção do Ocidente. São Paulo: Companhia das Letras, 2012.

SANTOS, Vanessa Sardinha dos. Brasil escola. Disponível em: https://brasilescola.uol.com.br/curiosidades/o-que-foi-perdido-no-incendio-museu-nacional.htm. Acesso em: 26 maio 2020.

TURINI, Leide Alvarenga. A crítica da história linear e da ideia de progresso: um diálogo com Walter Benjamin e Edward Thompson. Educação e Filosofia, São Paulo, v. 18, n. 35/36, p. 93-125, jan. 2004.

VALENTE, Rubens. Os fuzis e as flechas: a história de sangue e resistência indígena na ditadura. São Paulo: Companhia das Letras, 2017.

YEATS, W. B. Nineteen Hundred and Nineteen. Coleção The Tower, 1928. (Tradução do Poema Mil novecentos e dezenove). 